\title{
Prevalence and predictor for malignancy of contralateral thyroid nodules in patients with unilateral PTMC: a systematic review and meta-analysis
}

\author{
Weidi Wang(1) Lingjun Kong' ${ }^{2}$, Hongkun Guo ${ }^{3}$ and Xiangjin Chen ${ }^{2}$ \\ ${ }^{1}$ Department of Emergency, The First Affiliated Hospital of Fujian Medical University, Fuzhou, Fujian, China \\ 2Department of Thyroid and Breast, The First Affiliated Hospital of Fujian Medical University, Fuzhou, Fujian, China \\ ${ }^{3}$ Department of Emergency, The First Affiliated Hospital of Fujian Medical University, Fuzhou, Fujian, China \\ Correspondence should be addressed to X Chen: rjbhcxj@sina.com
}

\begin{abstract}
Background: The presence of clinically negative nodules on the contralateral lobe is common in patients with unilateral papillary thyroid microcarcinoma (PTMC). The appropriate operational strategies of contralateral thyroid nodules remain controversial. In this study, we analyzed clinical features that could be predictors for malignancy of contralateral thyroid nodules coexisting with diagnosed unilateral PTMC. Methods: The literatures published from January 2000 to December 2019 were searched in PubMed, Cochrane Library, Embase, Web of Science, CNKI, and Wan Fang database. Odds ratio (OR) with $95 \% \mathrm{Cl}$ was used to describe categorical variables. Heterogeneity among studies was examined by the $\mathrm{Q}$ test and $\mathrm{I}^{2}$ test; potential publication bias was detected by Harbord test and 'trim and fill' method.

Results: In this meta-analysis, 2541 studies were searched and 8 studies were finally included. The results showed that the rate of carcinoma in contralateral nodules was $23 \%(\mathrm{OR}=0.23,95 \% \mathrm{Cl}=0.18-0.29)$. The pooled data indicated that contralateral malignancy was not associated with age, gender, primary lesion size, ipsilateral central lymph node metastasis and multifocality of contralateral lesion. The following variables have correlations with an increased risk of contralateral malignancy: multifocality of primary carcinomas $(\mathrm{OR}=3.93,95 \% \mathrm{Cl}=2.70-5.73, P<0.0001)$, capsular invasion $(\mathrm{OR}=1.61,95 \% \mathrm{Cl}=1.10-2.36, P=0.01)$, and Hashimoto's thyroiditis $(\mathrm{OR}=1.57,95 \%$ $\mathrm{Cl}=1.13-2.20, P=0.008)$.

Conclusions: Based on our meta-analysis, the rate at which contralateral malignancies are preoperatively misdiagnosed as benign is $23 \%$. The risk factors for contralateral malignancy in unilateral PTMC patients with contralateral clinical negative nodules include multifocality of primary carcinomas, capsular invasion, and Hashimoto's thyroiditis.
\end{abstract}

\section{Key Words}

- unilateral PTMC

- risk factors

- contralateral thyroid nodules

- meta-analysis

\section{Introduction}

Papillary thyroid carcinoma (PTC) is the most common pathological subtype of thyroid carcinoma (TC). In recent years, the incidence of PTC is gradually increasing worldwide $(1,2)$. The increase in incidence is explained by the improvement of examination techniques, which have promoted the detection of unilateral papillary thyroid microcarcinoma (PTMC) (3). https://ec.bioscientifica.com https://doi.org/10.1530/EC-21-0164 (c) 2021 The authors Published by Bioscientifica Ltd
Endocrine Connections (2021) 10, 656-666 
PTMC has been regarded as indolent. It is controversial whether all patients with PTMC confined to the unilateral lobe determined by fine-needle aspiration (FNA) or clinical negative nodules in the contralateral lobe should undergo a total thyroidectomy (TT). Thyroid lobectomy alone may be sufficient for PTMC, which is considered as low-risk and unifocal tumor (4). A study evaluating the long-term effect of lobectomy showed that lobectomy (with isthmectomy) is effective for most patients with unilateral multifocal PTC (5). Moreover, the risk of injury to the contralateral parathyroid gland and recurrent laryngeal nerve during TT is also increased. Besides, patients undergoing TT need lifelong thyroid hormone replacement, which requires more compliance.

So far, only a few studies have analyzed the risk factors for malignancy of contralateral nodules in unilateral PTMC patients, and the incidence of carcinoma in contralateral nodules obtained from each study is inconsistent $(7.7 \% \sim 43.3 \%)(6,7,8,9,10,11,12,13)$. In addition, relevant studies have not found consistent risk factors. We aimed to identify specific types of unilateral PTMC patients, whose contralateral nodules present a high risk of carcinoma. According to our data, the risk factors for contralateral malignancy in unilateral PTMC patients with contralateral clinical negative nodules include multifocality of primary carcinomas, capsular invasion, and Hashimoto's thyroiditis.

\section{Methods}

This systematic review was conducted following the criteria of the Preferred Reporting Items for Systematic Review and Meta-Analyzes (PRISMA) (14). (Supplementary Table 1, see section on supplementary materials given at the end of this article). The protocol for this systematic review was registered on PROSPERO (http://www.crd.york.ac.uk/ prospero/) under No. CRD42021232568.

\section{Search strategies}

We accessed PubMed, Cochrane Library, Embase, Web of Science, China National Knowledge Infrastructure (CNKI), and Wan Fang database to search for potential studies from January 2000 to December 2019. The following keywords ((PTMC OR PTC OR microcarcinoma) AND (thyroid nodules) AND (risk or predictive or factor) AND (bilateral or contralateral or unilateral)) were used. No language restriction was applied. To expand our search, references of the retrieved articles were also screened to identify additional studies.

\section{Selection criteria}

Two reviewers independently read the titles and abstracts of all articles to search for relevant studies. We included studies fulfilling all the following criteria: (i) prospective or retrospective original studies; (ii) all of the patients were diagnosed unilateral PTMC preoperatively by US or FNA; (iii) all of the patients underwent TT or nearly total thyroidectomy; (iv) none of the patients had clinical evidence of contralateral thyroid carcinoma preoperatively (If any suspicious ultrasound images exist, FNA was performed); (v) sufficient data provided concerning the feature of patients.

Studies were excluded if (i) they were case reports, reviews, conference abstracts, and posters; (ii) patients with other pathologic types of thyroid carcinoma or preoperatively bilateral thyroid cancer; (iii) patients who had undergone head and neck irradiation or oncological surgery radiotherapy; (iv) patients with a family history of thyroid cancer.

We define contralateral carcinoma as a nodule in the contralateral lobe that was diagnosed as benign by ultrasound (US) or FNA preoperatively, but the nodule was diagnosed as malignant by postoperative pathological examination.

\section{Data extraction}

Two reviewers independently selected studies for inclusion and exclusion. Discrepancies in the selection were resolved by consensus. The following variables were recorded: first author, journal and year of publication, countries of study, number of carcinomas, number of cases, the features of patients (age, sex, size of primary lesion, ipsilateral central lymph node metastasis, multifocality of primary lesion, multifocality of contralateral lesion, capsular invasion, and Hashimoto's thyroiditis). If necessary, the corresponding authors of the studies were contacted to obtain additional information.

\section{Quality assessment}

Two independent evaluators used the Newcastle-Ottawa quality assessment scale (NOS) (15). The content of the evaluation includes the following four aspects: quality of selection, comparability, exposure, and outcome of study participants. The total score of NOS (maximum 9 
points) is obtained according to the specific requirements of each item above. Studies with a total score $>7$ were considered as high quality. We assessed the overall certainty of the evidence for each outcome using the Grading Recommendations Assessment, Development and Evaluation (GRADE) approach (16). Disagreements for GRADE assessments were resolved by discussion. We used the Guideline Development Tool (https://www.gradepro. org) to formulate the summary of findings table.

\section{Statistical analysis}

We utilized Review Manager (Revman) for statistical analysis. Heterogeneity was quantified using the Cochran Q test and $\mathrm{I}^{2}$ statistics. A fixed-effects model or random-effects model was used to calculate the pooled odds ratio (OR) with its $95 \%$ CI. A $P$ value of less than 0.05 was considered as statistically significant in the present meta-analysis. $\mathrm{I}^{2}>50 \%$ was regarded to indicate significant heterogeneity, where random-effects model would be used. Otherwise, fixed-effects model would be applied. Sensitivity analysis for each study, especially the study with low-quality control, large weight and results that greatly differ from other works. These studies were excluded to recalculate the number of combined effects, which were compared with the previous meta-analysis. We selected a conservative conclusion if the sensitivity analysis is inconsistent with the original results. For publication bias evaluation, we utilized Harbord test (17). Although planned, we did not construct funnel plots to assess for publication bias as these are inaccurate when less than ten trials are included in the analysis. If the Harbord test showed a $P$ value $<0.05$, we assumed publication bias was present. The Duval \& Tweedie non-parametric 'trim and fill' method was used to adjust for it (18).

\section{Results}

\section{Study selection}

The comprehensive computer study search revealed 2541 potentially relevant studies. According to the above criteria, a total of 8 studies and 1221 patients were included in this meta-analysis. The main characteristics of the included studies are summarized in Table 1. A flow chart of the selection process is presented in Fig. 1.

\section{Quantitative analysis}

The included studies were statistically heterogeneous $\left(\mathrm{I}^{2}=84.6 \%\right)$ for the prevalence of carcinoma, which ranged from $7.7 \%$ to $43.3 \%$. A random-effects model shows the pooled prevalence of carcinoma in contralateral nodules in the eight included studies was $23 \%(95 \% \mathrm{CI}=0.17-0.29)$ (Fig. 2).

\section{Meta-analysis}

Meta-analysis indicated that contralateral malignancy was not associated with age, sex, primary lesion size, ipsilateral central lymph node metastasis, and multifocality of the contralateral lesion. Forest plots are shown in Fig. 3 (see Supplementary Figs 1, 2, 3, 4, 5 for more details). A summary of the meta-analytic statistics is presented in Table 2 .

Table 1 Characteristics of the included studies.

\begin{tabular}{|c|c|c|c|}
\hline Study (author, year) & Study design & Country & $\begin{array}{l}\text { Median age } \\
\text { (range) }\end{array}$ \\
\hline Bom Seok Koo 2010 (6) & Retrospective & Korea & $\begin{array}{l}48 \\
(26-84)\end{array}$ \\
\hline Connor Matt 2011 (7) & Retrospective & USA & $\begin{array}{l}43 \\
(13-64)\end{array}$ \\
\hline Li Wei Meng 2012 (8) & Retrospective & China & $\begin{array}{l}48 \\
(19-80)\end{array}$ \\
\hline Ming Yang 2013 (9) & Retrospective & China & $\begin{array}{l}56 \\
(42-64)\end{array}$ \\
\hline Sung Yong Choi 2013 (10) & Retrospective & Korea & $\begin{array}{l}51 \\
(26-76)\end{array}$ \\
\hline Han Feng Wan 2014 (11) & Retrospective & China & $\begin{array}{l}40.5 \\
(16-67)\end{array}$ \\
\hline Young Chan Lee 2015 (12) & Retrospective & Korea & $\begin{array}{l}53 \\
(-)\end{array}$ \\
\hline Zeng Gui Wu 2016 (13) & Retrospective & China & $\begin{array}{l}48 \\
(-)\end{array}$ \\
\hline
\end{tabular}

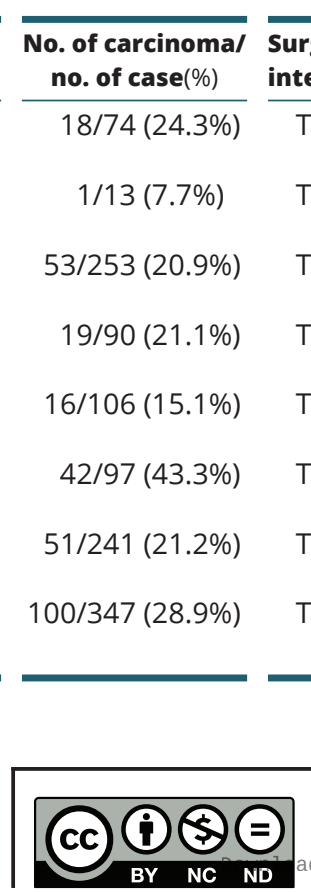

This work is licensed under a Creative Commons Attribution-NonCommercial-NoDerivatives 4.0 Internationab ficense.ifica.com at 04/26/2023 01:29:21AM 


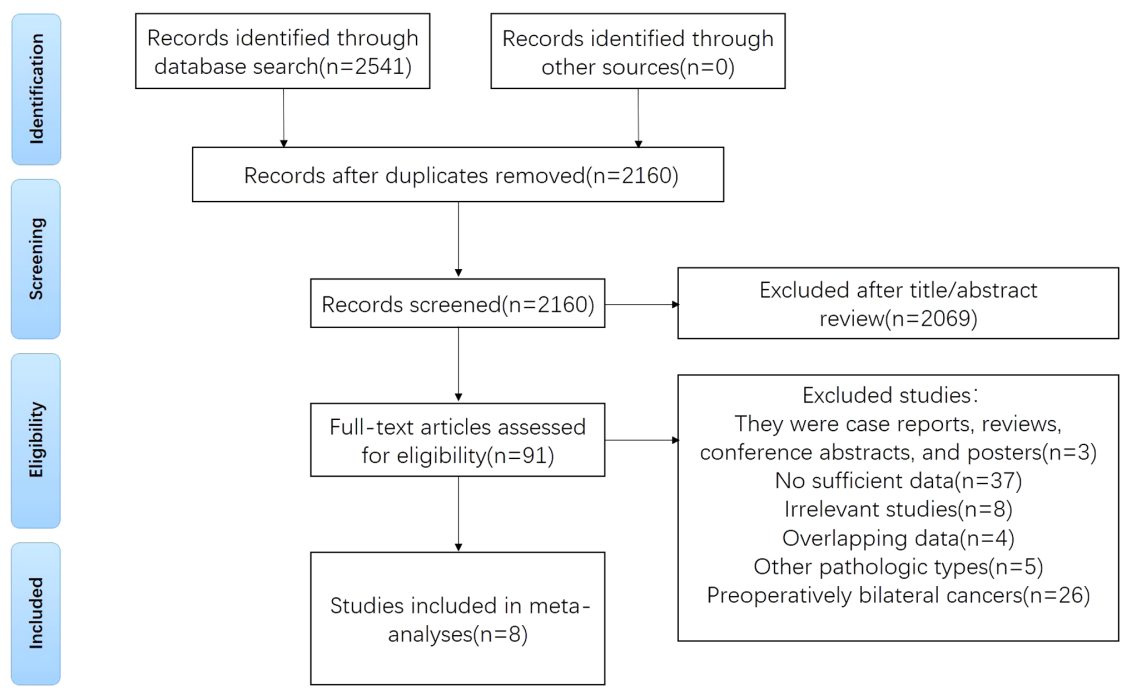

\section{Figure 1}

Flowchart of the study selection.

\section{Hashimoto's thyroiditis}

This article includes four studies on Hashimoto's thyroiditis (HT) $(8,9,12,13)$. The heterogeneity test showed no significant heterogeneity among these studies $(P=0.24$, $\left.\mathrm{I}^{2}=28 \%\right)$. The results indicated that HT was associated with a high rate of malignancy in contralateral nodules $(\mathrm{OR}=1.57,95 \% \mathrm{CI}=1.13-2.20, P=0.008)$ (Fig. 4). The same results were obtained after sensitivity analysis. Publication bias was evaluated by Harbord test, which revealed that the impact of publication bias was minimal on the metaanalysis study.

\section{Multifocality of primary lesion}

Four studies were included in the analysis of multifocality of primary lesion $(6,8,9,13)$. We found a positive correlation between multifocality of primary lesion and contralateral malignancy $(\mathrm{OR}=3.93,95 \% \mathrm{CI}=2.70-5.73$, $P<0.0001$ ) (Fig. 5). The same results were obtained after sensitivity analysis.

\section{Capsular invasion}

Four studies relating to capsular invasion were included $(6,8,9,13)$. A fixed-effects model was applied due to insignificant heterogeneity $\left(P=0.38, \mathrm{I}^{2}=2 \%\right)$. It is shown that patients with capsular invasion exhibited a 1.61-fold risk of contralateral malignancy $(\mathrm{OR}=1.61,95 \% \mathrm{CI}=1.10$ 2.36, $P=0.01$ ) compared with the patients without capsular invasion (Fig. 6). The same results were obtained after sensitivity analysis.

\section{Sensitivity analyses}

Sensitivity analysis was performed by excluding one study at a time, where no significant influence on the stability of the results was identified.

The size of primary lesion was not associated with contralateral carcinoma $(\mathrm{OR}=1.18,95 \% \mathrm{CI}=0.67-2.09$, $P=0.57$ ). Following the leave-one-out method (sensitivity analysis), the results were statistically significant only when Meng (2012) is excluded (OR=1.71, 95\%

\begin{tabular}{l} 
Study \\
\hline Koo 2010 \\
Connor 2011 \\
Meng 2012 \\
Chio 2013 \\
Yang 2013 \\
Wan 2014 \\
Lee 2015 \\
Wu 2016 \\
Overall \\
Heterogeneity: $\tau^{2}=0.01, \mathrm{I}^{2}=84.60 \%, \mathrm{H}^{2}=6.49$ \\
Test of $\theta_{\mathrm{i}}=\theta_{\mathrm{j}}: \mathrm{Q}(7)=32.79, \mathrm{p}=0.00$ \\
Test of $\theta=0: \mathrm{z}=7.16, \mathrm{p}=0.00$
\end{tabular}

Effect Size Weight with $95 \% \mathrm{Cl} \quad(\%)$

$0.24[0.15,0.34] 11.44$ $0.08[-0.07,0.22] \quad 8.63$ $0.21[0.16,0.26] 14.31$ $0.15[0.08,0.22] 13.30$ $0.21[0.13,0.30] 12.29$ $0.43[0.33,0.53] 11.38$ $0.21[0.16,0.26] 14.23$ 0.29 [ $0.24,0.34] 14.43$

0.23 [ $0.17,0.29]$

Figure 2

Forest plots of the pooled prevalence of carcinoma in contralateral nodules. https://ec.bioscientifica.com https://doi.org/10.1530/EC-21-0164 (c) 2021 The authors Published by Bioscientifica Ltd
This work is licensed under a Creative Commons Attribution-NonCommercial-NoDerivatives 4.0 Internationab ficense.ifica.com at 04/26/2023 01:29:21AM 
A

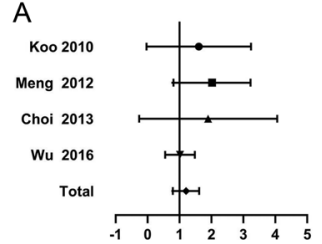

B

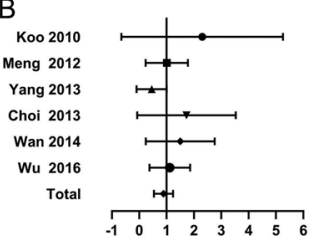

C

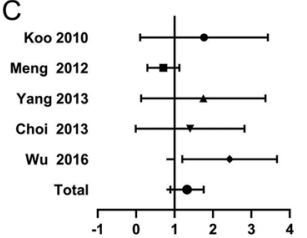

D

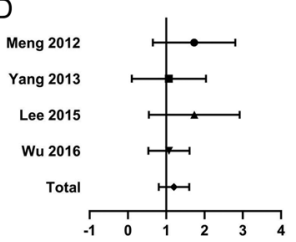

$\mathrm{E}$

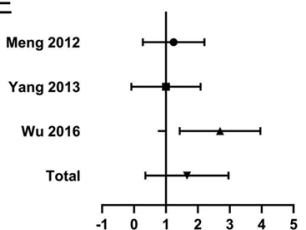

Figure 3

Forest plot for the meta-analysis of studies reporting on the association with the risk of contralateral carcinoma of (A) age, (B) sex, (C) size of primary lesion, (D) ipsilateral central lymph node metastasis, (E) multifocality of contralateral lesion.

$\mathrm{CI}=1.15-2.56, P=0.008$ ) (Supplementary Fig. 6), but the results were reversed compared with the results before sensitivity analysis. Due to the low stability of the results, a conservative conclusion was taken and the correlation was not considered. In addition, the study of Meng (2012) (8) was considered as one of the sources of heterogeneity.

\section{Publication bias and safety}

Evaluation of publication bias by the Harbord test is shown in Table 2. The Harbord test result for multifocality of primary lesion suggests that the presence of publication biasmay distort the meta-analysis. The Duval \& Tweedie non-parametric 'trim and fill' method was employed and generally resulted in similar conclusions of the unadjusted random-effect model of 3.93 (95\% $\mathrm{CI}=2.70-5.73)$; we calculated a summary adjusted OR of 3.75 (95\% CI $=2.64-$ 5.32). Publication bias was not evident from the Harbord test for any other clinical feature. The GRADE approach was adopted to evaluate the overall certainty of evidence and 'Summary of findings' tables were presented (Table 3).

\section{Discussion}

\section{Debate extent of surgery for PTMC}

For unilateral PTMC patients with thyroid nodules in the contralateral lobe that was preoperatively diagnosed as benign, the appropriate operational strategy of thyroid nodules remains controversial. When a unilateral PTMC coexists with contralateral nodules diagnosed by US as benign, most clinicians tend to perform a TT for worrying the risk of recurrence in remnant thyroid tissue.

However, the recent consensus statements from the Japan Association of Endocrine Surgery show that no evidence exists that patients with benign nodules should be excluded for active surveillance of PTMC (19).

Furthermore, for low-risk PTMC, the few recurrences that develop during long-term follow-up are readily detected and appropriately treated with no impact on survival (20). Given that PTMC typically exhibits low malignancy, good prognosis (3), it is widely recognized that 'delayed treatment' does not affect the prognosis of patients with low-risk PTMC.

A large number of studies have investigated the clinical features as potential predictors for malignancy of contralateral thyroid nodules coexisting with proven unilateral PTMC; however, the outcomes of these studies are discrepant. Here, we conducted a meta-analysis of eight retrospective studies that evaluated the possible correlation between carcinoma in contralateral nodules and related clinical-pathological features of PTMC patients.

\section{Risk factors}

\section{Age}

Age is closely related to the prognosis of PTMC. The cutoff point of age in the studies included was 45 years old. However, a multicenter retrospective study found that by increasing the cut-off point of age to 55 years old, about $17 \%$

Table 2 Summary of data synthesis.

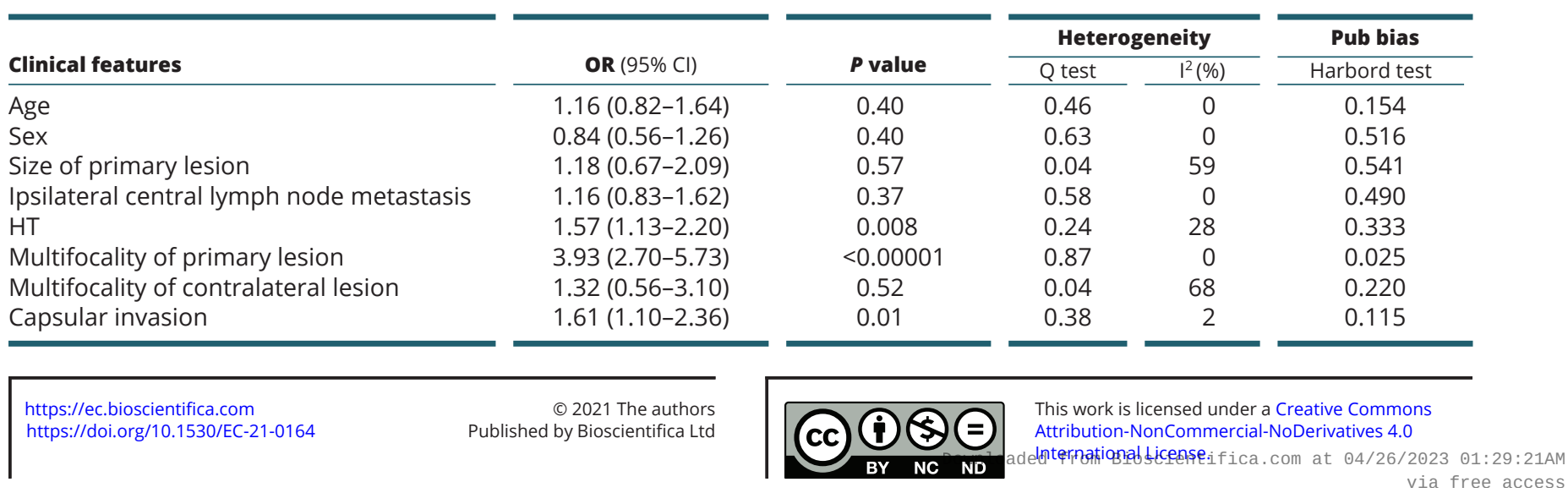




\begin{tabular}{|c|c|c|c|c|c|c|c|c|c|c|}
\hline \multirow[b]{2}{*}{ Study or Subgroup } & \multicolumn{2}{|c|}{ Hashimoto thyroiditis+ } & \multicolumn{2}{|c|}{ Hashimoto thyroiditis- } & \multirow{2}{*}{\multicolumn{2}{|c|}{$\begin{array}{l}\text { Odds Ratio } \\
\text { M-H. Fixed. } 95 \% \text { Cl Year }\end{array}$}} & \multirow{2}{*}{\multicolumn{3}{|c|}{$\begin{array}{c}\text { Odds Ratio } \\
\text { M-H. Fixed. } 95 \% \mathrm{Cl}\end{array}$}} & \\
\hline & Events & Total & Events & Total & & & & & & \\
\hline Meng LW 2012 & 38 & 146 & 15 & 107 & $23.8 \%$ & $2.16[1.12,4.17] 2012$ & & & $\rightarrow-$ & \\
\hline Yang M 2013 & 16 & 57 & 3 & 33 & $5.1 \%$ & $3.90[1.04,14.61] 2013$ & & & & \\
\hline Young CL 2015 & 15 & 63 & 36 & 178 & $26.7 \%$ & $1.23[0.62,2.45] 2015$ & & & & \\
\hline Zeng GW 2016 & 26 & 82 & 74 & 265 & $44.4 \%$ & $1.20[0.70,2.05] 2016$ & & & - & \\
\hline Total $(95 \% \mathrm{Cl})$ & & 348 & & 583 & $100.0 \%$ & $1.57[1.13,2.20]$ & & & 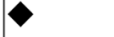 & \\
\hline Total events & 95 & & 128 & & & & & & & \\
\hline
\end{tabular}

\section{Figure 4}

Forest plots of the association between HT and contralateral carcinoma.

of the patients have a lower pathological stage compared to the 45 years old patients. However, there was no significant difference in the overall survival rate in this group of patients (21). The American Joint Committee on Cancer (AJCC) 8th edition for TC adjusted the age cut-off point from 45 to 55 years. This adjustment avoided overtreatment of low-risk patients. Meanwhile, Jeon et at. reported that age over 50 is closely related to PTMC progression (22). Kwong et al. reported that the prevalence of thyroid nodules increases with age but the risk of malignancy is reduced (23).

At present, there is no conclusion on the correlation between age and contralateral carcinoma. Our metaanalysis found that age is not a risk factor for malignancy in the contralateral nodules.

\section{Sex}

TC has a high incidence in women. Several studies have suggested that this phenomenon is related to the overexpression of estrogen receptors in TC since ER- $\alpha$ promotes the growth and progress of PTC (24). Male gender was identified as a risk factor for malignancy of indeterminate thyroid nodules (25).

On one hand, this work showed that there was no correlation between sex and contralateral carcinoma. Small number of included samples may cause the result. On the other hand, a recent meta-analysis shows that the male gender is associated with a high risk of recurrence in PTC patients (26). Further genomic and large-scale population epidemiological studies are required to understand the mechanism underlying the sex differences.

\section{Multifocality of primary lesion}

In this study, multifocality is defined as multiple primary foci that exist only in unilateral glands and are not related to contralateral nodules.

This meta-analysis shows consistent results as demonstrated by several previous studies that the multifocality of the primary tumor is an important risk factor for contralateral cancer, regardless of whether there are contralateral nodules $(27,28)$. Recently, some studies have reported that the multifocal PTCs are multiple synchronous primary tumors arising from independent clones $(29,30)$. Shattuck et al. analyzed the pattern of $\mathrm{X}$ chromosome inactivation in 17 cases of highly differentiated multifocal PTC and suggested that PTC may have an independent genetic origin (31). Therefore, most guidelines recommend total/subtotal thyroidectomy for PTMC, with multifocal primary tumors, regardless of stage.

It is worth noting that multifocality indicated by preoperative ultrasound could not be used as a prediction for malignancy, a final surgical strategy should be based on pathological results such as frozen section. This suggests that preoperative ultrasound is insufficient to evaluate the foci (12). A TT is required to reduce recurrence when

\begin{tabular}{lrrrrr} 
& \multicolumn{3}{c}{ Multifocality } & \multicolumn{3}{c}{ Single focality } \\
Study or Subgroup & Events & Total & Events & Total & Weight \\
\hline Bon SK 2010 & 3 & 5 & 15 & 69 & $4.0 \%$ \\
Meng LW 2012 & 26 & 62 & 27 & 191 & $33.7 \%$ \\
Yang M 2013 & 10 & 23 & 9 & 67 & $12.1 \%$ \\
Zeng GW 2016 & 38 & 76 & 62 & 271 & $50.2 \%$ \\
Total (95\% CI) & & 166 & & 598 & $100.0 \%$ \\
Total events & 77 & & 113 & \\
Heterogeneity: Tau $^{2}=0.00 ;$ Chi $^{2}=0.72, \mathrm{df}=3(\mathrm{P}=0.87) ;\left.\right|^{2}=0 \%$ \\
Test for overall effect: $\mathrm{Z}=7.13(\mathrm{P}<0.00001)$
\end{tabular}

Odds Ratio

M-H. Random, 95\% Cl Year

$5.40[0.83,35.33] 2010$

$4.39[2.29,8.39] 2012$

$4.96[1.68,14.64] 2013$

$3.37[1.98,5.74] 2016$

$3.93[2.70,5.73]$

Figure 5

Forest plots of the association between multifocality of primary lesion and contralateral carcinoma.

https://ec.bioscientifica.com https://doi.org/10.1530/EC-21-0164 (c) 2021 The authors Published by Bioscientifica Ltd M-H, Random, $95 \% \mathrm{Cl}$

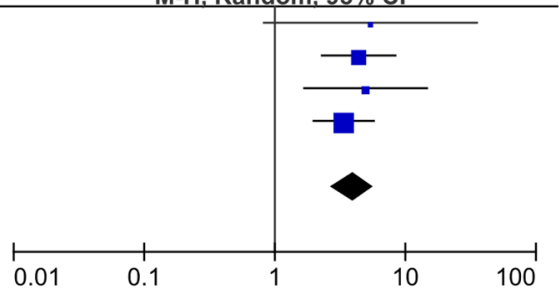




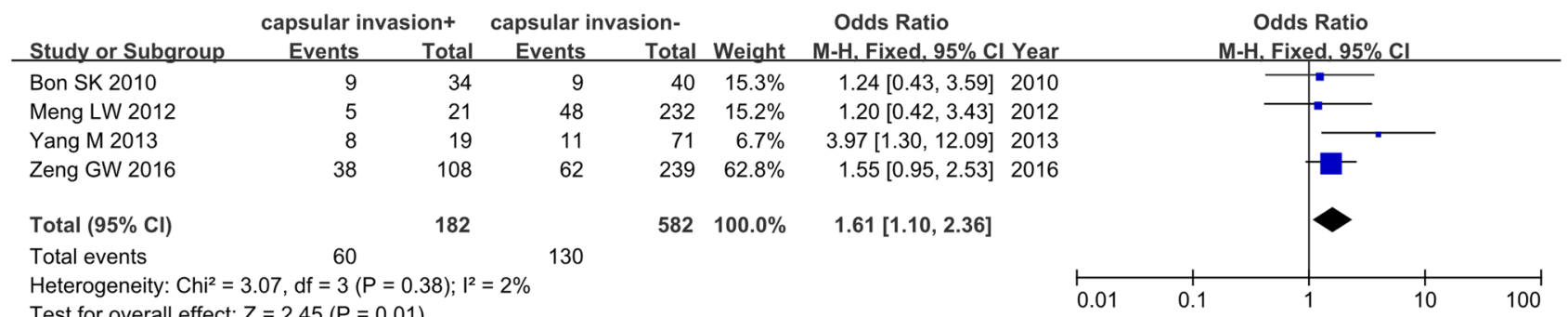

Figure 6

Forest plots of the association between capsular invasion and contralateral carcinoma.

the frozen section results show that the primary tumor is multifocal PTMC.

\section{Size of primary lesion}

Tumor size is an important factor affecting the prognosis of TC. The heterogeneity among the included studies is significant and the results are unstable. Unfortunately, the correlation between the size of primary lesions and contralateral carcinoma cannot be determined. Feng et al. demonstrated that tumor $>1 \mathrm{~cm}$ was an independent predictor of contralateral carcinoma (32). In contrast, Park et al. suggested that the size of the primary tumor could not be a predictor for contralateral carcinoma (33). Meanwhile, in a study that followed 992 patients with benign thyroid nodules for 5 years, Durant et al. reported an increase in diameter for at least $2 \mathrm{~mm}$ in $15.4 \%$ of the nodules (34). However, the significance of this growth pattern is unclear, as changes in the size of nodules are not an effective predictor of malignancy (35).

Although tumor size is an important factor affecting the prognosis of PTMC, we could not draw definitive conclusions regarding the possible association between the size of primary lesions and the existence of contralateral carcinoma.

\section{Multifocality of contralateral lesion}

So et al. reported that the presence of contralateral nodules is a predictor of carcinoma on the contralateral lobe of unilateral PTMC (36). Lee et al. showed that the

Table 3 GRADE summary of findings.

\begin{tabular}{|c|c|c|}
\hline Outcomes & $\begin{array}{l}\text { No of participants } \\
\text { (studies), follow up }\end{array}$ & $\begin{array}{l}\text { Certainty of the } \\
\text { evidence (GRADE) }\end{array}$ \\
\hline Age & $\begin{array}{l}764 \text { (4 observational } \\
\text { studies) }\end{array}$ & $\begin{array}{l}\bigoplus \bigoplus \bigcirc \bigcirc \\
\text { Low }\end{array}$ \\
\hline Sex & $\begin{array}{l}967 \text { ( } 6 \text { observational } \\
\text { studies) }\end{array}$ & $\begin{array}{l}\bigoplus \bigoplus \bigcirc \bigcirc \\
\text { Low }\end{array}$ \\
\hline Size of primary lesion & $\begin{array}{l}601 \text { (5 observational } \\
\text { studies) }\end{array}$ & $\begin{array}{l}\bigoplus \bigoplus \bigcirc \\
\text { Low }\end{array}$ \\
\hline CLNM & $\begin{array}{l}890 \text { (4 observational } \\
\text { studies) }\end{array}$ & $\underset{\text { Low }}{\oplus \bigoplus \mathrm{C}}$ \\
\hline HT & $\begin{array}{l}931 \text { ( } 4 \text { observational } \\
\text { studies) }\end{array}$ & $\underset{\text { Low }}{\bigoplus \bigoplus \bigcirc \bigcirc}$ \\
\hline $\begin{array}{l}\text { Multifocality of } \\
\text { primary lesion }\end{array}$ & $\begin{array}{l}764 \text { (4 observational } \\
\text { studies) }\end{array}$ & $\begin{array}{l}\bigoplus \bigcirc \bigcirc \bigcirc \\
\text { Very low }\end{array}$ \\
\hline $\begin{array}{l}\text { Multifocality of } \\
\text { contralateral lesion }\end{array}$ & $\begin{array}{l}690 \text { (3 observational } \\
\text { studies) }\end{array}$ & $\bigoplus \bigoplus_{\text {Very low }} \bigcirc$ \\
\hline Capsular invasion & $\begin{array}{l}764 \text { (4 observational } \\
\text { studies) }\end{array}$ & $\bigoplus_{\text {Low }} \oplus \bigcirc \bigcirc$ \\
\hline
\end{tabular}

\begin{tabular}{|c|c|c|}
\hline \multirow[b]{2}{*}{$\begin{array}{l}\text { Relative effect* } \\
\qquad(95 \% \mathrm{Cl})\end{array}$} & \multicolumn{2}{|c|}{ Anticipated absolute effects } \\
\hline & $\begin{array}{l}\text { Risk with } \\
\text { benign nodule }\end{array}$ & $\begin{array}{l}\text { Risk difference } \\
\text { contralateral cancer }\end{array}$ \\
\hline OR $1.16(0.82-1.64)$ & 228 per 1000 & $\begin{array}{l}27 \text { more per } 1000 \text { ( } 33 \\
\text { fewer to } 98 \text { more) }\end{array}$ \\
\hline OR $0.84(0.56-1.26)$ & 262 per 1000 & $\begin{array}{l}32 \text { fewer per } 1000 \text { (96 } \\
\text { fewer to } 47 \text { more) }\end{array}$ \\
\hline OR 1.18 (0.67-2.09) & 195 per 1000 & $\begin{array}{c}27 \text { more per } 1000 \text { (55 } \\
\text { fewer to } 141 \text { more) }\end{array}$ \\
\hline OR $1.16(0.83-1.62)$ & 237 per 1000 & $\begin{array}{l}28 \text { more per } 1000 \text { ( } 32 \\
\text { fewer to } 98 \text { more) }\end{array}$ \\
\hline OR $1.57(1.13-2.20)$ & 220 per 1000 & $\begin{array}{c}87 \text { more per } 1000 \text { ( } 22 \\
\text { more to } 163 \text { more) }\end{array}$ \\
\hline OR $3.93(2.70-5.73)$ & 189 per 1000 & $\begin{array}{c}289 \text { more per } 1000 \text { (197 } \\
\text { more to } 383 \text { more) }\end{array}$ \\
\hline OR $1.32(0.56-3.10)$ & 204 per 1000 & $\begin{array}{l}49 \text { more per } 1000 \text { (79 } \\
\text { fewer to } 239 \text { more) }\end{array}$ \\
\hline OR $1.61(1.10-2.36)$ & 223 per 1000 & $\begin{array}{c}93 \text { more per } 1000 \text { ( } 17 \\
\text { more to } 181 \text { more) }\end{array}$ \\
\hline
\end{tabular}

*The risk in the intervention group (and its $95 \% \mathrm{Cl}$ ) is based on the assumed risk in the comparison group and the relative effect of the intervention (and its $95 \% \mathrm{Cl}$ ); aThe Harbord test result for multifocality of primary lesion suggests that the presence of publication bias may distort the meta-analysis; ${ }^{b} \mathrm{High}$ $I^{2}(68 \%)$ and non-overlapping $\mathrm{Cl}$ suggest that important inconsistency which lowers our certainty in effect; ' Wide Cls do not exclude important benefit or harm which lowers our certainty in effect.

GRADE Working Group grades of evidence - High certainty: we are very confident that the true effect lies close to that of the estimate of the effect; Moderate certainty: we are moderately confident in the effect estimate, the true effect is likely to be close to the estimate of the effect, but there is a possibility that it is substantially different; Low certainty: our confidence in the effect estimate is limited, the true effect may be substantially different from the estimate of the effect; Very low certainty: we have very little confidence in the effect estimate, the true effect is likely to be substantially different from the estimate of effect.

https://ec.bioscientifica.com https://doi.org/10.1530/EC-21-0164 (c) 2021 The authors Published by Bioscientifica Ltd

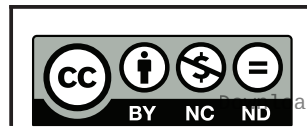

This work is licensed under a Creative Commons Attribution-NonCommercial-NoDerivatives 4.0 International License.ifica com at $04 / 26 / 2023$ 01:29:21AM 
contralateral multiple non-suspicious nodules were more likely to coexist with carcinoma (37). This phenomenon may be related to intrathyroidal metastasis of tumors, which has been confirmed by a number of studies $(38,39)$. Frate et al. pointed out that for the general population, the probability of thyroid cancer in nodules is not related to the number of nodules (40).

Given that low certainty of the evidence and low stability of the results included in our meta-analysis, it is not clear whether the multifocality of contralateral nodules is correlated with contralateral carcinoma. Lin et al. reported that $49.3 \%$ of patients with thyroid cancer smaller than $1 \mathrm{~cm}$ could not be accurately diagnosed by preoperative FNA (41). Furthermore, other studies have pointed out that ultrasound, FNA and ultrasound combined with FNA all have high sensitivity and accuracy in the diagnosis of the thyroid nodule in the $>1 \mathrm{~cm}$ group, without significant differences (42). We speculate that these results may arise from the fact that the background of multiple nodules makes it more difficult to determine nodules, which leads to misdiagnosis of contralateral nodules before operation.

\section{Ipsilateral central lymph node metastasis}

Cervical lymph node metastasis (CLNM) is the most common form of PTC metastasis. It occurs in the early stage of the disease, especially in the ipsilateral cervical lymph node (43). Previous study has shown that central lymph node metastasis is a predictor for malignancy of contralateral thyroid nodules, which can be evaluated by preoperative ultrasound examination and intraoperative frozen biopsy (44). The results of this work show that ipsilateral central lymph node metastasis is not correlated with contralateral carcinoma.

In order to reduce the risk of local recurrence, Asian national guidelines recommend prophylactic central lymph node dissection if allowed. By contrast, routine lymph node dissection is less performed in PTMC patients with clinically negative central lymph nodes (cNO) and more postoperative $\mathrm{I}^{131}$ treatment is selected in Europe and the United States $(4,45)$. Different treatment strategies lead to a higher detection rate of ipsilateral CLNM in Asian studies, and the resulting selection bias may be one of the reasons for significant heterogeneity.

\section{Hashimoto's thyroiditis}

Hashimoto's thyroiditis is a common autoimmune disease of the thyroid. This meta-analysis suggests that PTMC patients with HT exhibited a 1.56-fold higher risk of contralateral malignancy, suggesting that HT was a risk factor for cancer in contralateral nodules. The relationship between TC and HT has evoked broad interest in the field.

On one hand, Liu et al. conducted a populationbased study of HT. The study showed that HT was strongly correlated with PTMC, and HT was an important risk factor for PTMC in young people aged between 18 and 30 years (46). A meta-analysis involving 64,628 patients showed that HT was associated with a high risk of PTC (47). It suggested that excessive lymphocyte infiltration could release higher levels of inflammatory factors, such as interferon- $\gamma$, tumor necrosis factor- $\alpha$, etc. which may lead to an increased risk of cancer (48).

On the other hand, PTC with HT is characterized by smaller tumor size, less capsule infiltration, less lymph node metastasis and better prognosis, which may represent weaker invasiveness and the regulation of autoimmune response (49). However, there are also studies suggesting that HT is not an independent risk factor of contralateral cancer (50).

In view of the correlation between HT and PTMC, when frozen section results show the coexistence of PTMC and HT, TT should be adopted to avoid misdiagnosis of contralateral malignant nodules.

\section{Capsular invasion}

When the primary tumor is growing close to the thyroid capsule, it is very likely to invade capsule tissue. Once the capsule invasion occurs, it may further lead to an extraglandular invasion, including recurrent laryngeal nerve, esophagus, trachea and other organs. TT is recommended for patients with extra-glandular invasion (4).

Thyroid capsule in front of the trachea is discontinuous, and the possible existence of adipose tissue and skeletal muscle tissue in the thyroid tissue itself may lead to clinical pathologists' misjudgment of minimal extraglandular invasion of PTMC. Moreover, some studies have shown that there was no significant difference in the prognosis between patients with minor extraglandular invasion and patients without capsule invasion $(51,52)$.Therefore, we chose capsule invasion as a potential predictor for contralateral cancer rather than extraglandular invasion or micro-extraglandular invasion.

Previous studies have suggested that contralateral nodule with carcinoma is not associated with capsule invasion (53). However, our results showing that patients with capsular invasion exhibited a 1.61-fold increased risk of contralateral malignancy. Given that the thyroid 
capsule is rich in lymphatic vessels, capsule invasion may lead to an increase in the risk of metastasis. Although most guidelines do not specify the scope of resection of PTMC with capsule invasion, total / subtotal thyroidectomy should be performed actively considering the high possibility of extraglandular invasion.

\section{Limitations}

This meta-analysis has several limitations. First, in order to execute the inclusion criteria in strict rotation, the sample size of this meta-analysis was relatively small. Secondly, several detailed information of the tumor was not recorded, such as the location of the primary tumor in the glandular lobe, the size and location of the contralateral nodule. The loss of information may lead to inevitable biases. Thirdly, most of the patients from the included studies were Asian. Given the differences between Asian and Western populations with regard to culture, genetic background, lifestyle, so that the conclusions of our study may be applicable for Asian populations only, more studies from other regions or countries should be included to support the results. Fourthly, the judgment of contralateral nodules is based on preoperative FNA and ultrasound, even if the same standards are followed, errors may be caused by different operators and pathological interpretations.

\section{Conclusion}

In conclusion, for unilateral PTMC patients, the rate at which contralateral carcinomas are preoperatively misdiagnosed as benign is $23 \%$. The risk factors for contralateral malignancy in unilateral PTMC patients with contralateral clinical negative nodules include multifocality of primary carcinomas, capsular invasion, and HT. When frozen section examination reveals the above risk factors, TT/subtotal TT should be performed to avoid misdiagnosis as much as possible. For patients without high-risk factors, more conservative treatment can be tried, which can reduce the complications of operation and improve the compliance of patients.

\section{Supplementary materials}

This is linked to the online version of the paper at https://doi.org/10.1530/ EC-21-0164.

\section{Declaration of interest}

The authors declare that there is no conflict of interest that could be perceived as prejudicing the impartiality of this study.

\section{Funding}

This research did not receive any specific grant from any funding agency in the public, commercial or not-for-profit sector.

\section{Ethics statement}

The paper is exempted from ethical committee approval since this is a systematic review and meta-analysis.

\section{Author contribution statement}

XJ C, W D W and LJ K conceived and designed the experiments. W D W and LJ K performed the experiments and contributed analysis tools. W D W, LJ $\mathrm{K}$ and $\mathrm{H} \mathrm{K} \mathrm{G}$ analyzed the data. W D W wrote the paper.

\section{Acknowledgement}

Wei-Kun Huang, the English language editor, was responsible for correcting language and grammar issues.

\section{References}

1 Siegel RL, Miller KD \& Jemal A. Cancer statistics, 2020. CA: A Cancer Journal for Clinicians 2020 70 7-30. (https://doi.org/10.3322/caac.21590)

2 Chen AY, Jemal A \& Ward EM. Increasing incidence of differentiated thyroid cancer in the United States, 1988-2005. Cancer 2009115 3801-3807. (https://doi.org/10.1002/cncr.24416)

3 Du L, Wang Y, Sun X, Li H, Geng X, Ge M \& Zhu Y. Thyroid cancer: trends in incidence, mortality and clinical-pathological patterns in Zhejiang Province, Southeast China. BMC Cancer 201818291. (https://doi.org/10.1186/s12885-018-4081-7)

4 Haugen BR, Alexander EK, Bible KC, Doherty GM, Mandel SJ, Nikiforov YE, Pacini F, Randolph GW, Sawka AM, Schlumberger M, et al. 2015 American Thyroid Association management guidelines for adult patients with thyroid nodules and differentiated thyroid cancer: the American Thyroid Association guidelines task force on thyroid nodules and differentiated thyroid cancer. Thyroid 201626 1-133. (https://doi.org/10.1089/thy.2015.0020)

5 Huang H, Liu S, Xu Z, Ni S, Zhang Z \& Wang X. Long-term outcome of thyroid lobectomy for unilateral multifocal papillary carcinoma. Medicine 201796 e7461. (https://doi.org/10.1097/ MD.0000000000007461)

6 Koo BS, Lim HS, Lim YC, Yoon YH, Kim YM, Park YH \& Rha KS. Occult contralateral carcinoma in patients with unilateral papillary thyroid microcarcinoma. Annals of Surgical Oncology 201017 1101-1105. (https://doi.org/10.1245/s10434-009-0906-6)

7 Connor MP, Wells D \& Schmalbach CE. Variables predictive of bilateral occult papillary microcarcinoma following total thyroidectomy. Otolaryngology-Head and Neck Surgery 2011144 210-215. (https://doi. org/10.1177/0194599810391616)

8 Meng LW, Huang LM, Xu CY \& Zhang W. Managements of small thyroid nodules with contralateral papillary thyroid microcarcinoma. Chinese Journal of Otorhinolaryngology Head and Neck Surgery 201247 827-830.

9 Yang M \& Yu C. Analysis of clinical characteristics of patients with unilateral PTMC complicated with contralateral thyroid nodules. Journal of Chinese Physician 2013015 549-551. (https://doi. org/10.3760/cma.j.issn.1673-0860.2017.04.004)

10 Choi SY, Woo SH, Shin JH, Choi N, Son YI, Jeong HS, Baek CH \& Chung MK. Prevalence and prediction for malignancy of additional thyroid nodules coexisting with proven papillary thyroid microcarcinoma. Otolaryngology-Head and Neck Surgery 2013149 53-59. (https://doi.org/10.1177/0194599813482877) 
11 Wan H, Zhang B, Yan D \& Xu Z. Prediction of occult carcinoma in contralateral nodules for unilateral papillary thyroid carcinoma. Chinese Journal of Otorhinolaryngology Head and Neck Surgery 201449 881-884.

12 Lee YC, Eun YG, Sohn YM, Rhee SY, Hong IK, Chon S, Oh SJ \& Kim DY. Predictive factors for occult contralateral carcinoma in patients with unilateral papillary thyroid microcarcinoma by preoperative ultrasonographic and pathological features. World Journal of Surgery 201539 1736-1741. (https://doi.org/10.1007/s00268-015-3024-6)

13 Wu ZG, Yan XQ, Su RS, Ma ZS, Xie BJ \& Cao FL. How many contralateral carcinomas in patients with unilateral papillary thyroid microcarcinoma are preoperatively misdiagnosed as benign? World Journal of Surgery 201741 129-135. (https://doi.org/10.1007/s00268016-3701-0)

14 Moher D, Liberati A, Tetzlaff J \& Altman DG. Preferred reporting items for systematic reviews and meta-analyses: the PRISMA statement. British Medical Journal 2009339 b2535. (https://doi.org/10.1136/bmj.b2535)

15 Higgins J \& Green S Cochrane Handbook for Systematic Reviews for Interventions, Version 5.1.0 2011.

16 Guyatt GH, Oxman AD, Vist GE, Kunz R, Falck-Ytter Y, AlonsoCoello P, Schünemann HJ \& GRADE Working Group. GRADE: an emerging consensus on rating quality of evidence and strength of recommendations. BMJ 2008336 924-926. (https://doi.org/10.1136/ bmj.39489.470347.AD)

17 Harbord RM, Egger M \& Sterne JA. A modified test for small-study effects in meta-analyses of controlled trials with binary endpoints. Statistics in Medicine 200625 3443-3457. (https://doi.org/10.1002/ $\operatorname{sim} .2380)$

18 Duval S \& Tweedie R. Trim and fill: a simple funnel-plot-based method of testing and adjusting for publication bias in metaanalysis. Biometrics 201556 455-463. (https://doi.org/10.1111/j.0006341X.2000.00455.x)

19 Sugitani I, Ito Y, Takeuchi D, Nakayama H, Masaki C, Shindo H, Teshima M, Horiguchi K, Yoshida Y, Kanai T, et al. Indications and strategy for active surveillance of adult low-risk papillary thyroid microcarcinoma: consensus statements from the Japan Association of Endocrine Surgery Task Force on Management for Papillary Thyroid Microcarcinoma. Thyroid 202131 183-192. (https://doi.org/10.1089/ thy.2020.0330)

20 Park JH \& Yoon JH. Lobectomy in patients with differentiated thyroid cancer: indications and follow-up. Endocrine-Related Cancer 201926 R381-R393. (https://doi.org/10.1530/ERC-19-0085)

21 Ganly I, Nixon IJ, Wang LY, Palmer FL, Migliacci JC, Aniss A, Sywak M, Eskander AE, Freeman JL, Campbell MJ, et al. Survival from differentiated thyroid cancer: what has age got to do with it? Thyroid 201525 1106-1114. (https://doi.org/10.1089/thy.2015.0104)

22 Jeon MJ, Chung MS, Kwon H, Kim M, Park S, Baek JH, Song DE, Sung TY, Hong SJ, Kim TY, et al. Features of papillary thyroid microcarcinoma associated with lateral cervical lymph node metastasis. Clinical Endocrinology 201786 845-851. (https://doi. org/10.1111/cen.13322)

23 Kwong N, Medici M, Angell TE, Liu X, Marqusee E, Cibas ES, Krane JF, Barletta JA, Kim MI, Larsen PR, et al. The influence of patient age on thyroid nodule formation, multinodularity, and thyroid cancer risk. Journal of Clinical Endocrinology and Metabolism 2015100 4434-4440. (https://doi.org/10.1210/jc.2015-3100)

24 Huang Y, Dong W, Li J, Zhang H, Shan Z \& Teng W. Differential expression patterns and clinical significance of estrogen receptor- $\alpha$ and $\beta$ in papillary thyroid carcinoma. BMC Cancer 201414383. (https://doi.org/10.1186/1471-2407-14-383)

25 Hegedüs L. Clinical practice. The thyroid nodule. New England Journal of Medicine 2004351 1764-1771. (https://doi.org/10.1056/ NEJMcp031436)

26 Guo K \& Wang Z. Risk factors influencing the recurrence of papillary thyroid carcinoma: a systematic review and meta-analysis. International Journal of Clinical and Experimental Pathology $2014 \mathbf{7}$ 5393-5403.
27 Mantinan B, Rego-Iraeta A, Larrañaga A, Fluiters E, Sánchez-Sobrino P \& Garcia-Mayor RV. Factors influencing the outcome of patients with incidental papillary thyroid microcarcinoma. Journal of Thyroid Research 20122012 469397. (https://doi.org/10.1155/2012/469397)

28 Chen X, Zhong Z, Song M, Yuan J, Huang Z, Du J, Liu Y \& Wu Z. Predictive factors of contralateral occult carcinoma in patients with papillary thyroid carcinoma: a retrospective study. Gland Surgery 2020 9 872-878. (https://doi.org/10.21037/gs-19-157)

29 Park SY, Park YJ, Lee YJ, Lee HS, Choi SH, Choe G, Jang HC, Park SH, Park DJ \& Cho BY. Analysis of differential BRAF(V600E) mutational status in multifocal papillary thyroid carcinoma: evidence of independent clonal origin in distinct tumor foci. Cancer $2006 \mathbf{1 0 7}$ 1831-1838. (https://doi.org/10.1002/cncr.22218)

30 Giannini R, Ugolini C, Lupi C, Proietti A, Elisei R, Salvatore G, Berti P, Materazzi G, Miccoli P, Santoro M, et al. The heterogeneous distribution of BRAF mutation supports the independent clonal origin of distinct tumor foci in multifocal papillary thyroid carcinoma. Journal of Clinical Endocrinology and Metabolism 200792 3511-3516. (https://doi.org/10.1210/jc.2007-0594)

31 Shattuck TM, Westra WH, Ladenson PW \& Arnold A. Independent clonal origins of distinct tumor foci in multifocal papillary thyroid carcinoma. New England Journal of Medicine 2005352 2406-2412. (https://doi.org/10.1056/NEJMoa044190)

32 Feng JW, Ye J, Wu WX, Pan H, Qin AC, Jiang Y \& Wu BQ. Management of clinically solitary papillary thyroid carcinoma patients according to risk-scoring model for contralateral occult carcinoma. Frontiers in Endocrinology 202011 553577. (https://doi.org/10.3389/ fendo.2020.553577)

33 Park SY, Jung YS, Ryu CH, Lee CY, Lee YJ, Lee EK, Kim SK, Kim TS, Kim TH, Jang J, et al. Identification of occult tumors by wholespecimen mapping in solitary papillary thyroid carcinoma. EndocrineRelated Cancer 201522 679-686. (https://doi.org/10.1530/ERC-15-0152)

34 Durante C, Costante G, Lucisano G, Bruno R, Meringolo D, Paciaroni A, Puxeddu E, Torlontano M, Tumino S, Attard M, et al. The natural history of benign thyroid nodules. Journal of the American Medical Association 2015313 926-935. (https://doi.org/10.1001/ jama.2015.0956)

35 Nakamura H, Hirokawa M, Ota H, Kihara M, Miya A \& Miyauchi A. Is an increase in thyroid nodule volume a risk factor for malignancy? Thyroid 201525 804-811. (https://doi.org/10.1089/thy.2014.0567)

36 So YK, Kim MW \& Son YI. Multifocality and bilaterality of papillary thyroid microcarcinoma. Clinical and Experimental Otorhinolaryngology 20158 174-178. (https://doi.org/10.3342/ceo.2015.8.2.174)

37 Lee KJ, Cho YJ, Kim JG \& Lee DH. How many contralateral papillary thyroid carcinomas can be missed? World Journal of Surgery 201337 780-785. (https://doi.org/10.1007/s00268-013-1913-0)

38 Wang W, Wang H, Teng X, Wang H, Mao C, Teng R, Zhao W, Cao J, Fahey TJ \& Teng L. Clonal analysis of bilateral, recurrent, and metastatic papillary thyroid carcinomas. Human Pathology 201041 1299-1309. (https://doi.org/10.1016/j.humpath.2010.02.008)

39 Jovanovic L, Delahunt B, McIver B, Eberhardt NL, Bhattacharya A, Lea R \& Grebe SK. Distinct genetic changes characterise multifocality and diverse histological subtypes in papillary thyroid carcinoma. Pathology 201042 524-533. (https://doi.org/10.3109/00313025.2010.5 08780)

40 Frates MC, Benson CB, Doubilet PM, Kunreuther E, Contreras M, Cibas ES, Orcutt J, Moore FD, Larsen PR, Marqusee EN, et al. Prevalence and distribution of carcinoma in patients with solitary and multiple thyroid nodules on sonography. Journal of Clinical Endocrinology and Metabolism 200691 3411-3417. (https://doi.org/10.1210/jc.2006-0690)

41 Lin JD, Huang BY, Chao TC \& Hsueh C. Diagnosis of occult thyroid carcinoma by thyroid ultrasonography with fine needle aspiration cytology. Acta Cytologica 199741 1751-1756. (https://doi. org/10.1159/000333180)

42 Li J, Wang Q, Wang L, Wang J, Wang D, Xin Z, Liu Y \& Zhao Q. Diagnostic value of fine-needle aspiration combined with ultrasound

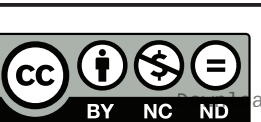

This work is licensed under a Creative Commons Attribution-NonCommercial-NoDerivatives 4.0 elnternationab ficense.ifica com at 04/26/2023 01:29:21AM 
for thyroid cancer. Oncology Letters 201918 2316-2321. (https://doi. org/10.3892/ol.2019.10584)

43 Li N, Cui M, Yu P \& Li Q. Correlations of lncRNAs with cervical lymph node metastasis and prognosis of papillary thyroid carcinoma. OncoTargets and Therapy 201912 1269-1278. (https://doi.org/10.2147/ OTT.S191700)

44 Chang YW, Kim HS, Jung SP, Kim HY, Lee JB, Bae JW \& Son GS. Significance of micrometastases in the calculation of the lymph node ratio for papillary thyroid cancer. Annals of Surgical Treatment and Research 201792 117-122. (https://doi.org/10.4174/ astr.2017.92.3.117)

45 Takami H, Ito Y, Okamoto T, Onoda N, Noguchi H \& Yoshida A. Revisiting the guidelines issued by the Japanese Society of Thyroid Surgeons and Japan Association of Endocrine Surgeons: a gradual move towards consensus between Japanese and western practice in the management of thyroid carcinoma. World Journal of Surgery $2014 \mathbf{3 8}$ 2002-2010. (https://doi.org/10.1007/s00268-014-2498-y)

46 Liu Y, Li C, Zhao W \& Wang Y. Hashimoto's thyroiditis is an important risk factor of papillary thyroid microcarcinoma in younger adults. Hormone and Metabolic Research 201749 732-738. (https://doi. org/10.1055/s-0043-117892)

47 Resende de Paiva C, Grønhøj C, Feldt-Rasmussen U \& von Buchwald C. Association between Hashimoto's thyroiditis and thyroid cancer in 64,628 patients. Frontiers in Oncology 2017 753. (https://doi. org/10.3389/fonc.2017.00053)
48 Fiore E, Latrofa F \& Vitti P. Iodine, thyroid autoimmunity and cancer. European Thyroid Journal 20154 26-35. (https://doi. org/10.1159/000371741)

49 Caturegli P, Remigis AD, Chuang K, Dembele M, Iwama A \& Iwama S. Hashimoto's thyroiditis: celebrating the centennial Through the lens of the Johns Hopkins Hospital surgical pathology records. Thyroid 201323 142-150. (https://doi.org/10.1089/thy.2012.0554)

50 Mukasa K, Noh JY, Kunii Y, Matsumoto M, Sato S, Yasuda S, Suzuki M, Ito $\mathrm{K} \&$ Ito K. Prevalence of malignant tumors and adenomatous lesions detected by ultrasonographic screening in patients with autoimmune thyroid diseases. Thyroid 201121 37-41. (https://doi. org/10.1089/thy.2010.0050)

51 Radowsky JS, Howard RS, Burch HB \& Stojadinovic A. Impact of degree of extrathyroidal extension of disease on papillary thyroid cancer outcome. Thyroid 201424 241-244. (https://doi.org/10.1089/thy.2012.0567)

52 Woo CG, Sung CO, Choi YM, Kim WG, Kim TY, Shong YK, Kim WB, Hong SJ \& Song DE. Clinicopathological significance of minimal extrathyroid extension in solitary papillary thyroid carcinomas. Annals of Surgical Oncology 2015 22(Supplement 3) S728-S733. (https:// doi.org/10.1245/s10434-015-4659-0)

$53 \mathrm{Lv}$ T, Zhu C \& Di Z. Risk factors stratifying malignancy of nodules in contralateral thyroid lobe in patients with pre-operative ultrasound indicated unilateral papillary thyroid carcinoma: A retrospective analysis from single centre. Clinical Endocrinology 201888 279-284. (https://doi.org/10.1111/cen.13506)

Received in final form 8 May 2021

Accepted 19 May 2021

Accepted Manuscript published online 19 May 2021 (c) 2021 The authors Published by Bioscientifica Ltd
This work is licensed under a Creative Commons Attribution-NonCommercial-NoDerivatives 4.0 Internationab ficense.ifica . com at 04/26/2023 01:29:21AM 